\title{
Shaking Table Test on 800 kV HV Reactor Composite Bushing Yuhan Sun ${ }^{1, a^{*}}$, Zhenlin Liu ${ }^{1, b}$, Sen Lin ${ }^{1, c}$, Zhigang Su ${ }^{1, d}$ \\ ${ }^{1}$ China Electric Power Research Institute, China asunyuhan11@126.com, bliuzhenlin@epri.sgcc.com.cn, linsen@epri.sgcc.com.cn, d'suzhigang@epri.sgcc.com.cn
}

Keywords: 800 kV HV reactor, composite bushing, shaking table test, seismic performance

\begin{abstract}
As a key component of power transmission and distribution systems, HV reactor bushing made of porcelain have suffered serious damage in previous earthquakes. In order to enhance seismic ability, the new type bushing made of composite material has been used in high seismic fortify-cation intensity projects. In this study, the $800 \mathrm{kV}$ HV reactor bushings were tested by shaking table. The test requirement in this analysis included: the selection of dynamic magnification factor, the selection of excited wave, the control of tolerance between input peak acceleration and output peak acceleration. During the shaking test, the dynamic characteristics, including frequency and damping ratio, and the seismic response of the composite bushing was obtained. Based on the analysis results of the bushing, the judgment of the seismic capacity was achieved.
\end{abstract}

\section{Introduction}

As the load-center substation of Sichuan-Tibet Power Grid Project, Batang 500kV Substation is located in Batang County, Ganzi Prefecture, Sichuan Province within the Songpan-Ganzi Orogenic Belt. The project region belongs to earthquake-prone zone with a number of fault zones distributed near the project region, which is a region with strong earthquake activities characterized by high intensity and low frequency, where medium- and small-scale earthquakes occur frequently, with some 868 earthquakes recorded within a 200km range just from 1975 to October 1977. Therefore, a study on the seismic capacity of the electrical equipment used in Batang Substation is of particular importance [1][2].

In this paper, a shaking table test is conducted on a $800 \mathrm{kV}$ HV composite bushing used for $500 \mathrm{kV}$ Substation in order to analyze the dynamic property and dynamic response of HV reactor composite bushing under the action of earthquakes, providing basis for application of composite bushings.

\section{Bushing seismic hazard analysis and research status quo in China and abroad}

2.1 Bushing seismic hazard analysis. As important electrical equipment in a substation, bushings of transformer and reactor are highly vulnerable for earthquakes. According to an incomplete statistics of the damages caused by Wenchuan Earthquake, bushings of 73 transformers of different voltage grades have been damaged [3].

According to a statistics of past earthquake hazards, bushings of transformer and reactor mainly experienced the following two kinds of damage:

(1) Cracked and torn bushing flanges. Under the action earthquake, transformer and reactor were displaced and the bushings were pulled at by high-voltage leads, resulting in long cracks in 
the flange between the bushing and oil tank holder or torn flange root, causing a loss of the equipment functions.

(2) Ruptured bushing root. Under the action of earthquake, root of the bushing became ruptured due to traction of the top-end flexible conductor, which caused a leakage of the insulating oil out of the bushing.

Main reasons justifying the high seismic vulnerability of the bushings include: With slender structure and low natural vibration frequency, the bushing is prone to resonance under the action of an earthquake, and the transformer and reactor bodies have a magnification effect on the ground motion, which can produce a very high bending moment and shear force at root of the bushing; the ceramic part itself is a fragile material with a poor deformability and insufficient strength, and the deformation at the connection of bushing and flange is out of tune, which together make it easier for damages to occur during an earthquake[4] [5].

2.2 Bushing seismic capacity research in China and abroad. Scholars from various countries have conducted a great deal of research on seismic capacity of transformer and reactor bushings[6] [7] [8]. Bellorini and Villaverde, etc. have respectively conducted dynamic property test of bushings installed on transformers and have obtained the frequency and damping ratio of the bushings.

Restrained by loading capacity of the shaking table, researchers usually conduct the test by utilizing bushing-steel frame system to replace bushing-transformer (reactor) system. From 1998 to 1999, PEER and University of California (USA) conducted shaking table test on transformer bushings of different sizes by fixing the ceramic bushings respectively on rigid frame and flexible frame. The tests indicates that seismic capacity of the bushings is much better than in actual condition when the connection rigidity is high, and that the provision of a restraining ring at root of the bushing can effectively prevent bushing displacement from happening.

With the progress of material science, composite materials are gradually applied in the field of electrical equipment thanks to their lighter weight and higher strength, etc. In respect of composite bushings, the relevant experimental studies are mainly focused on their mechanical properties, and there are few experimental studies being conducted on their seismic capacity, especially with respect to $800 \mathrm{kV}$ reactor composite bushings, there has not been any relevant track record of seismic simulation shaking table test.

\section{Test overview}

3.1 Shaking table and specimen parameters. The shaking table used for the present test has a table top measuring $6.0 \mathrm{~m} \times 6.0 \mathrm{~m}$, a maximum effective loading capacity of $800 \mathrm{kN}$ and a frequency range of $0.1 \mathrm{~Hz} \sim 50 \mathrm{~Hz}$. The controlled vibration mode is 3 directions and 6 degrees of freedom. The test specimen is a $800 \mathrm{kV} \mathrm{HV}$ reactor composite bushing, and its composite material is glass fiber reinforced plastics. Table 1 shows basic parameters of the specimen.

Tab.1 Basic parameter of $800 \mathrm{kV} \mathrm{HV}$ reactor composite bushing

\begin{tabular}{|c|c|c|c|c|c|c|}
\hline Model & Weight $/ \mathrm{kg}$ & Total length $/ \mathrm{mm}$ & $\begin{array}{l}\text { Length of bushing } \\
/ \mathrm{mm}\end{array}$ & $\begin{array}{c}\text { O.D. of } \\
\text { bushing /mm }\end{array}$ & I.D. of bushing /mm & $\begin{array}{c}\text { Elastic } \\
\text { modulus/MPa } \\
\end{array}$ \\
\hline $\begin{array}{c}\text { BRDLW } \\
-800 / 800-3\end{array}$ & 2800 & 10748 & 7402 & 512 & 482 & $1.25 \times 10^{4}$ \\
\hline
\end{tabular}

The specimen is mounted on a support, and the support is fixed with the shaking table by 
bolts. See Fig. 1 for specimen mounting.

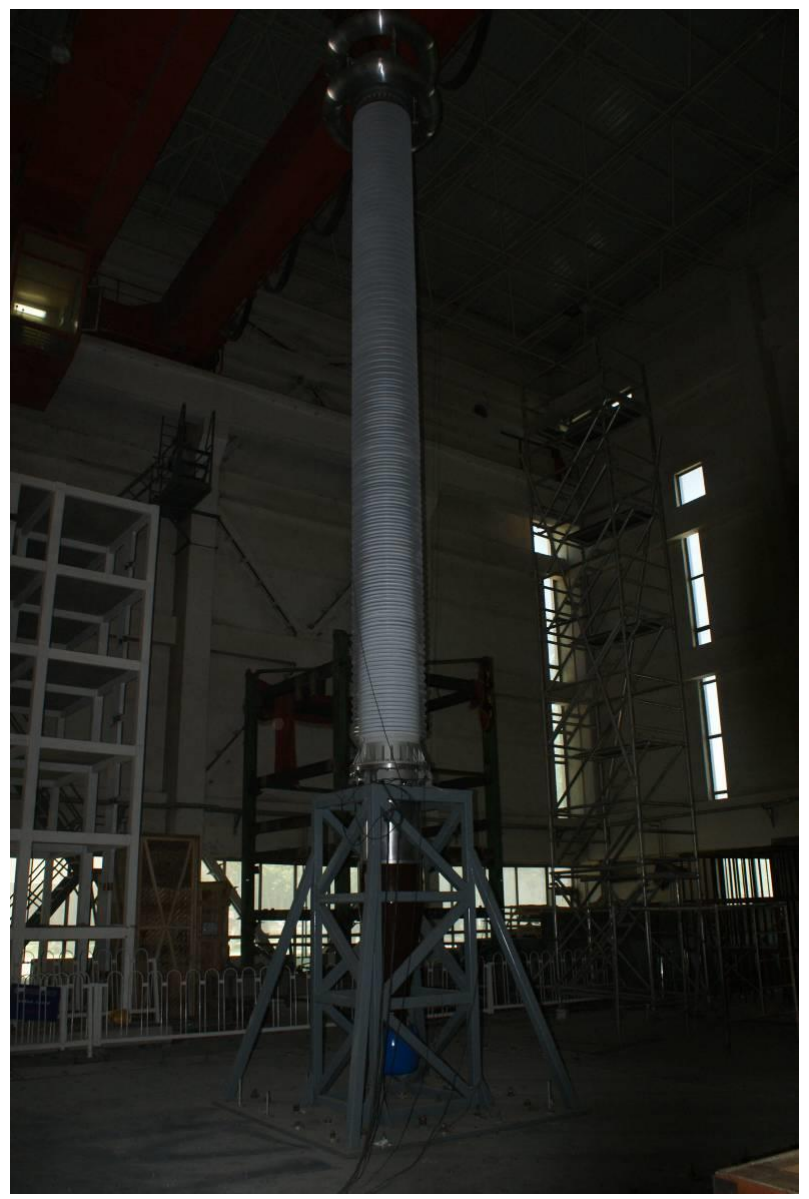

Fig.1 $800 \mathrm{kV}$ HV reactor composite bushing fixed on shaking table

3.2 Test input. According to "Code for Seismic Design of Electrical Installations" (GB 50260-2013), this test selects resonance beat wave to serve as seismic excitation for unidirectional horizontal seismic input. The acceleration time-history of the resonance beat wave can be determined according to the following stipulation:

When $t \geq 5 T$, then $a=0$

When $0 \leq t \leq 5 T$, $a$ value can be defined according to the following formula:

$$
\begin{gathered}
a=a \times \sin (\omega t) \times \sin [(\omega t) / 10] \\
a_{s}=\alpha \times 0.75 a_{0}
\end{gathered}
$$

Where, $a$ is the horizontal acceleration of each time-history in $\mathrm{g} ; t$ is the time in $\mathrm{s} ; T$ is the basic natural vibration cycle in $\mathrm{s} ; a_{s}$ is the maximum horizontal acceleration of ground motion for time-history analysis in $\mathrm{g} ; \alpha$ is the dynamic response magnification coefficient; $a_{0}$ is the design basic acceleration of ground motion in $\mathrm{g}$; and $\omega$ is the basic natural vibration circular frequency of the system in the testing direction in $\mathrm{Hz}$.

According to the relevant specification of Literature on earthquake fortification and equipment dynamic magnification coefficient, the design basic acceleration of ground motion is taken as $0.4 \mathrm{~g}$ for the present test and the dynamic response magnification coefficient is taken as 2.0. And by taking into account the beat wave deduction coefficient shown in Formula (2), the actual peak acceleration input for the present test is $0.75 \times 2 \times 0.4 \mathrm{~g}=0.6 \mathrm{~g}$. Fig. 2 shows the resonance beat waveform inputted for the test. 


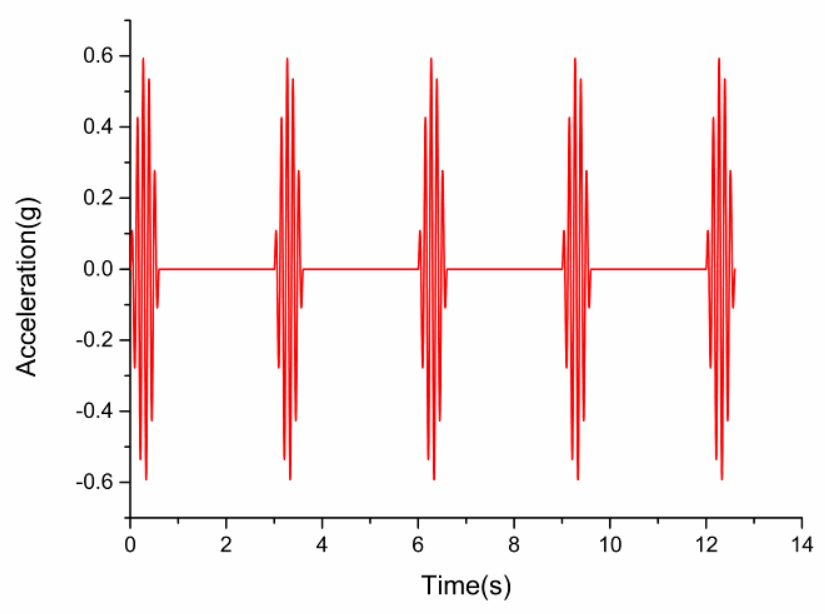

Fig.2 Acceleration history input of shaking table

3.3 Test condition. This test is divided into 5 test conditions in total. The various test conditions and purposes are shown in Table 2. In Table 2, Test Condition 1 is a white noise input lasting for a duration of no less than $60 \mathrm{~s}$, and the purpose is to obtain the frequency and damping ratio of the specimen; Test Condition 2 is a peak acceleration resonance beat wave input, and the purpose is to calibrate the table top peak acceleration output through multiple iteration of the acceleration, and obtain the dynamic response of the critical part of the specimen; Test Condition 3 is a white noise input lasting for a duration of no less than $60 \mathrm{~s}$, and the purpose is to check to see whether there is any functional damage to the specimen before and after Test Condition 2; Test Condition 4 is a resonance beat wave input for a peak acceleration of $0.6 \mathrm{~g}$, and the purpose is to obtain the dynamic response of the critical part of the specimen; Test Condition 5 is a white noise input lasting for a period of no less than 60s, and the purpose is to check whether there is any functional damage to the specimen before and after Test Condition 4.

This test adopts unidirectional horizontal excitation, and the excitation direction (Direction $\mathrm{X}$ ) is as shown in Fig. 3.

Tab.2 Shaking table test conditions

\begin{tabular}{|c|c|c|c|c|}
\hline Test condition & Seismic excitation wave & Excitation direction & $\begin{array}{l}\text { Peak acceleration input of } \\
\text { shaking table } / g\end{array}$ & Test purpose \\
\hline 1 & White noise & $\mathrm{X}$ & $0.05 \sim 0.08$ & Testing the dynamic characteristics \\
\hline 2 & Resonance beat wave & $\mathrm{X}$ & 0.15 & $\begin{array}{c}\text { Obtaining dynamic response of critical } \\
\text { portion }\end{array}$ \\
\hline 3 & White noise & $\mathrm{X}$ & $0.05 \sim 0.08$ & $\begin{array}{c}\text { Check to see if there is any functional } \\
\text { damage to the equipment }\end{array}$ \\
\hline 4 & Resonance beat wave & $\mathrm{X}$ & 0.6 & $\begin{array}{c}\text { Obtaining dynamic response of critical } \\
\text { portion }\end{array}$ \\
\hline 5 & White noise & $\mathrm{X}$ & $0.05 \sim 0.08$ & $\begin{array}{c}\text { Check to see if there is any functional } \\
\text { damage to the equipment }\end{array}$ \\
\hline
\end{tabular}

3.4 Arrangement of measuring points. To study the seismic response of the specimen, strain gauges are attached in the corresponding positions on the root of the bushing in the vibrating direction (Direction X), as shown in Fig. 3, and acceleration sensors are installed respectively on the shaking table top, support top end and specimen top end. There are 2 strain measuring points 
and 3 acceleration measuring points. Fig. 3 shows a layout of the specimen measuring points.

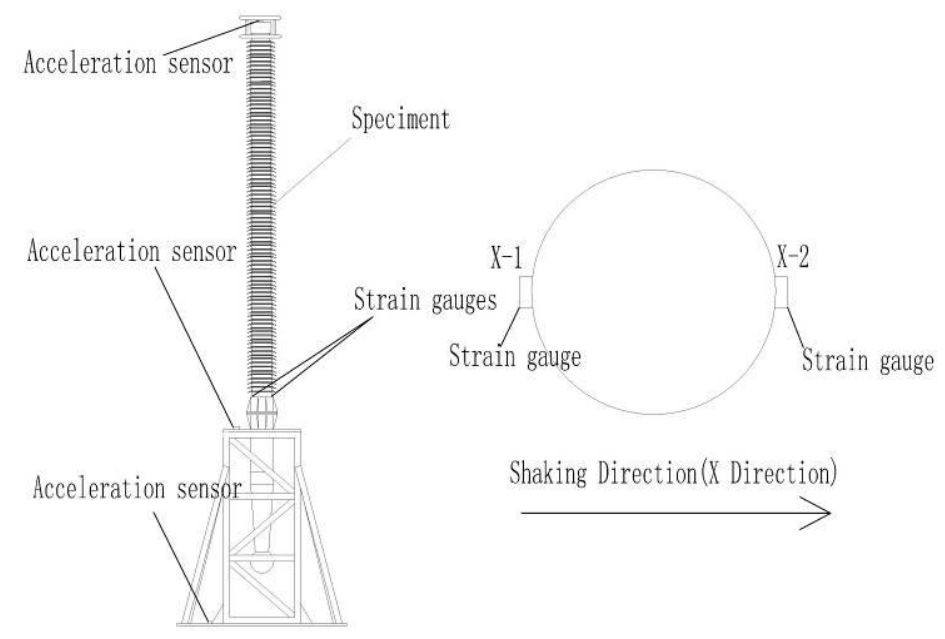

Fig.3 Layout of measuring points

\section{Test results}

4.1 White noise scanning result. Table 3 shows the dynamic characteristics of $800 \mathrm{kV}$ HV reactor composite bushing after input of white noise under Test Conditions 1, 3 and 5.

Tab.3 Frequency and damping of $800 \mathrm{kV} \mathrm{HV}$ reactor composite bushing

\begin{tabular}{cccc}
\hline Test condition & Model order & Frequency/Hz & Damping ratio/\% \\
\hline 1 & $1 \mathrm{st}$ & 1.57 & 11.7 \\
3 & $1 \mathrm{st}$ & 1.63 & 10.4 \\
5 & $1 \mathrm{st}$ & 1.53 & 10.2 \\
\hline
\end{tabular}

It can be seen from Table 3 that frequency of the specimen before the test was $1.57 \mathrm{~Hz}$, which is within the predominant frequency range $(1 \mathrm{~Hz} \sim 10 \mathrm{~Hz})$ of ground motion; damping ratio of the specimen before the test was $11.7 \%$ while damping ratio of traditional ceramic bushings is mostly below $5 \%$. Therefore, when compared with ceramic bushings, composite bushings have a bigger damping ratio, and produce an obvious damping effect on seismic response.

By comparing Test Conditions 1, 3 and 5, it can be seen that there has been a small change in both frequency and damping ratio of the specimen before versus after the test. When comparing Test Condition 1 with Test Condition 5, frequency of the specimen drops $2.55 \%$ and the damping ratio drops $12.82 \%$. Possible causes of such phenomenon include loosened bolts at the flanged connection as well as loosened bolt connection between the support and the table top during test among other causes. However, since the amplitude of change in dynamic characteristics of the specimen is small, the specimen can be deemed as having no obvious functional damage.

4.2 Results of seismic test. Table 4 shows the results of seismic test of the specimen. Since the specimen is fixed on the shaking table top by connecting with the support, its actual acceleration input equals to the acceleration of the top end of the support. It can be seen from Table 4 that due to the dynamic response magnification effect of the support, the peak acceleration value of the specimen actually inputted is $0.63 \mathrm{~g}$, greater than the peak acceleration value outputted by the table top. 
Tab.4 Seismic responses of $800 \mathrm{kV}$ HV reactor composite bushing

\begin{tabular}{|c|c|c|c|c|c|}
\hline \multirow{2}{*}{$\begin{array}{c}\text { Test } \\
\text { condition }\end{array}$} & \multicolumn{2}{|c|}{ Peak strain $/ \mu \varepsilon$} & \multicolumn{2}{|c|}{ Peak acceleration/g } & \multirow{2}{*}{$\begin{array}{c}\text { Maximum relative } \\
\text { displacement of top end } \\
/ \mathrm{mm}\end{array}$} \\
\hline & Measuring point $\mathrm{X}-1$ & Measuring point $\mathrm{X}-2$ & Top end of support & Top end of equipment & \\
\hline 2 & 977.49 & 841.30 & 0.234 & 0.630 & 86.09 \\
\hline 4 & 2994.64 & 2498.36 & 0.675 & 1.908 & 242.46 \\
\hline
\end{tabular}

According to the elastic modulus of the composite material made available by the manufacturer, the peak strain at the measuring points is converted into peak stress, and the displacement angle (ratio of maximum relative displacement to height of specimen) of the specimen is figured out according to the maximum relative displacement of the top end of the specimen. The calculated results are shown in Table 5.

Tab.5 Stress and angle of displacement of $800 \mathrm{kV} \mathrm{HV}$ reactor composite bushing

\begin{tabular}{cccc}
\hline \multirow{2}{*}{ Test condition } & \multicolumn{2}{c}{ Peak stress/MPa } & $\begin{array}{c}\text { Maximum angle of displace of } \\
\text { specimen /rad }\end{array}$ \\
\cline { 2 - 4 } & $\mathrm{X}-1$ measuring point & $\mathrm{X}-2$ measuring point & 0.80 \\
2 & 12.22 & 10.52 & 2.26 \\
\hline
\end{tabular}

It can be seen from Table 5 that under Test Conditions 2 and 4, the maximum stress of the bushing root is respectively $12.22 \mathrm{MPa}$ and $37.43 \mathrm{MPa}$, which are respectively $15.28 \%$ and $46.79 \%$ of the maximum mechanical load stress of the specimen (80MPa was given by the manufacturer). Stress allowance of the specimen is quite big, and the specimen has not been damaged during the test; Under Test Condition 4, the maximum angle of displacement of the specimen is 2.26rad.

A statistics is conducted of the seismic response ratio under these two test conditions (response under Test Condition 4/response under Test Condition 2), and the results are shown in Table 6.

Tab.6 Response ratios between the fourth condition and the second condition

\begin{tabular}{cccc}
\hline $\begin{array}{c}\text { Ratio of peak acceleration of top } \\
\text { end of support }\end{array}$ & $\begin{array}{c}\text { Ratio of peak acceleration of top } \\
\text { end of equipment }\end{array}$ & $\begin{array}{c}\text { Ratio of peak acceleration at X-1 } \\
\text { measuring point }\end{array}$ & $\begin{array}{c}\text { Ratio of peak acceleration at } \\
\text { X-2 measuring point }\end{array}$ \\
\hline 2.88 & 3.03 & 3.06 & 2.97 \\
\hline
\end{tabular}

It can be seen from Table 6 that the ratio of the same seismic response of the specimen under the two test conditions approximates to the ratio of peak acceleration (ie., peak acceleration of the top end of the support) actually inputted for the specimen for the two test conditions, and it can thus be deemed that as the peak acceleration inputted for the specimen increases, the seismic response and peak acceleration of the specimen approximately appear to be in a relationship of linear change.

\section{Conclusions}

(1) 1 st order frequency of the $800 \mathrm{kV} \mathrm{HV}$ reactor composite bushing was $1.57 \mathrm{~Hz}$, which is within the predominant frequency range $(1 \mathrm{~Hz} 10 \mathrm{~Hz})$ of ground motion; damping ratio of the specimen before the test was $11.7 \%$. Compared with the damping ratio of traditional ceramic bushings, composite bushings have a bigger damping ratio, and produce an obvious damping effect on seismic response.

(2) When the design basic acceleration of ground motion is $0.4 \mathrm{~g}$, and under the condition of resonance beat wave input of the dynamic magnification coefficient of the equipment proper, the 
maximum stress of $800 \mathrm{kV}$ reactor composite bushing is $37.43 \mathrm{MPa}$. Thus, the equipment stress safety margin is bigger.

(3) During the test, the maximum displacement angle at the equipment top end was $2.26 \mathrm{rad}$, where the displacement response is fairly big. Therefore, when designing a substation based on electrical equipment using composite bushings, analysis should conducted of the redundant length of the flexible conductors at the top end of the bushings, so as to ensure that the bushings are not damaged due to pulling and extracting on the conductors under seismic action.

(4) As the peak acceleration inputted for the equipment increases, the seismic response and peak acceleration of the equipment approximately appear to be in a relationship of linear change. Therefore, when it is difficult to input high-level acceleration of ground motion, the seismic response of the equipment under the action of high-level acceleration of ground motion can be inferred from the equipment response under the action of low-level acceleration of ground motion, so as to provide a basis for seismic design and seismic capacity evaluation of the equipment.

\section{References}

[1] China Earthquake Administration Wenchuan Earthquake Emergency Headquarters. Wenchuan earthquake disaster assessment report[R] . Beijing: China Earthquake Administration, 2008.

[2] CHENG Yongfeng, ZHU Quanjun, LU Zhicheng. Progress and development trend on seismic measures of electric power equipments in transformer substation [J] Power System Technology, 2008, 32(22) : 84-89.

[3] Zhenlin Liu, Zebing Dai and Zhicheng Lu: Weibull Distribution Based Seismic Vulnerability Analysis of Porcelain Power Equipment. Power System Technology. 2014, 38(4): 1076-1081. In Chinese.

[4] Yu Yongqing, Li Guangfan, Li Peng, et al. Investigation and analysis of electric equipment damage in Sichuan power grid caused by Wenchuan Earthquake[J]. Power System Technology, 2008, 32(11) :1-6.

[5] Xianzheng Meng, Zebing Dai ,Zhicheng Lu, Zhubing Zhu, Po Gao: Shaking Table Test for Seismic Performance of 500kV Arrester. Electric Power Construction. 2014, 35(1): 35-39. In Chinese.

[6] Bellorini S, Bettinali F. Seismic qualification of transformer high voltage bushings. IEEE Trans. Power Deliv., 1998,13(4): 1208-1213.

[7] QIU Ning, CHENG Yongfeng, ZHONG Min, et al. Progress and prospect in seismic research of $1000 \mathrm{kV}$ UHV AC electrical equipment[J] . High Voltage Engineering, 2015, 41(5) : 1732-1739.

[8] Filiatrault A, Matt H. Experimental seismic response of high-voltage transformer -bushing systems. Earthqu. Spectra, 2005,21:1009-1025. 